\title{
Spontaneous Mutation in Spheroplasts of Escherichia coli
}

\author{
By F. J. RYAN, T. OKADA AND T. NAGATA \\ Department of Zoology, Columbia University, New York, U.S.A.
}

(Received 4 April 1962)

\begin{abstract}
SUMMARY
Spheroplast suspensions containing as few as one rod in a thousand were made with Escherichia coli $\left(15 \mathrm{his}^{-}\right)$by the use of penicillin. These spheroplasts could be reverted to the rod state with efficiency approaching $100 \%$. Spontaneous mutation from histidine requirement to nonrequirement was observed in these spheroplasts, in which cell division did not take place.
\end{abstract}

\section{INTRODUCTION}

The mechanism of induced mutation has been investigated profitably along several lines but less is known about spontaneous mutation (Ryan, 1963). Some studies have been made with a histidineless strain of Escherichia coli (15 his-) in a non-dividing condition (Ryan, 1955, 1959; Ryan \& Kiritani, 1959; Ryan, Rudner, Nagata \& Kitani, 1959). The method involves distributing a culture into several hundred tubes containing a defined medium without histidine. When the concentration of organisms is about $1 \times 10^{7} / \mathrm{ml}$. the cultures are so clear that overgrowth of his $^{+}$mutants which might be present is easily recognized through the development of turbidity. At $20^{\circ}$, his ${ }^{+}$mutants, initially present at the time of distribution, overgrow in about $100 \mathrm{hr}$. Thereafter, for several hundred hours new overgrowths, in tubes that did not receive a pre-existing $\mathrm{his}^{+}$mutant, occur because of $\mathrm{his}^{+}$ mutants arising during the stationary phase. Since the medium used does not contain histidine it might be expected that the his $^{-}$organisms do not grow or divide; in fact, while the total count remains constant, the number of viable bacteria usually decreases by death during a long incubation. This fact may seem to indicate that the mutation occurs in non-dividing organisms. It does not, however, exclude the possibility of a cell turnover in which a cryptic lysis and replacement might balance one another. If this were the case, mutation in non-dividing bacteria could occur as . an error in replication of the chromosome (or of DNA) during the cell division required for replacement. Much effort has been expended in examining this possibility by several methods (Ryan, 1959; Ryan, Nakada \& Schneider, 1961). These attempts, which included reconstruction and penicillin experiments and the determination of DNA, did not reveal any cell turnover or cell growth in the stationary phase. Each piece of evidence was, however, circumstantial and not critical; together the evidence pointed to the conclusion that the stationary-phase bacteria were not dividing; in fact they did not even seem to be engaged in a turnover of DNA. A system of his ${ }^{-}$spheroplasts was, therefore, developed in order to investigate the role played by enzymes which digest macromolecules. This system and the evidence that mutations occur in spheroplasts are presented herewith. 


\section{METHODS}

The media used were: Difco penassay broth, and penassay broth and $\mathbf{G} \& \mathbf{T}$ (Ryan, 1959) medium with $0.05 \%$ glucose, both containing $20 \%$ sucrose and $0.2 \% \mathrm{MgSO}_{4} .7 \mathrm{H}_{2} \mathrm{O}$. The last two hypertonic solutions were the complete and defined media used for maintenance and enumeration of spheroplasts. To solidify them, $\mathbf{1 . 0} \%$ agar was added. Nutrient agar or G \& $\mathrm{T}$ agar supplemented with $\mathbf{0 . 5} \%$ yeast extract and $0.5 \%$ NZcase (YECA agar) were used for counting the rods. To make spheroplasts, penicillin was used at a concentration of 1000-2000 units/ml. in penassay broth.

The bacterium used was Escherichia coli $15 \mathrm{his}^{-}$col-r (colicine-resistant and simultaneously sensitive to all T phages; Ryan, Fried \& Mukai, 1955; Mukai, 1960) derived from $15 \mathrm{his}^{-} \mathrm{col}-\mathrm{s}$ which has been used for mutation experiments since 1955. This bacterium was grown in penassay broth at $37^{\circ}$ overnight with gentle rotation. Following this, $1.0 \mathrm{ml}$. of the fully grown suspension was introduced into $4.0 \mathrm{ml}$. of penassay broth and incubated at $37^{\circ}$ for $2-3 \mathrm{hr}$. in the same way, to bring the bacteria into the logarithmic phase. Suspensions thus obtained were used for all experiments.

The number of viable spheroplasts was determined by diluting the suspension in hypertonic penassay broth whereupon $0.5 \mathrm{ml}$. of a suitable dilution was plated in the same medium containing $1.0 \%$ agar melted and cooled to $45^{\circ}$. The colonies develop from both spheroplasts and rods; by subtracting the number of rods the number of spheroplasts can be calculated.

For enumerating the rods, the suspension was diluted with $0.85 \%$ saline solution and $0.1 \mathrm{ml}$. of the diluent was plated on nutrient agar medium. This procedure destroyed the spheroplasts but not the rods.

The procedure for making spheroplasts was almost the same as that of Lederberg (1956) and Lederberg \& St Clair (1958). The efficiency of forming spheroplasts and their stability was first compared at $37^{\circ}$ and at $20^{\circ}$. After introducing $1.0 \mathrm{ml}$. of cell suspension into $4.0 \mathrm{ml}$. of hypertonic penassay broth which contained 1000 units of penicillin $/ \mathrm{ml}$., the mixture was incubated at both temperatures. Samples were taken at 3 and at $8 \mathrm{hr}$. and the number of viable spheroplasts and rods was determined. As Fig. $1 a$ shows, spheroplasts formed at $20^{\circ}$ were more stable than those formed at $37^{\circ}$ and the efficiency of their formation (intact spheroplasts/rods) was rather better at $20^{\circ}$ than at $37^{\circ}$. Figs. $1(b)$ and $(c)$ show data obtained from spheroplast preparations at $20^{\circ}$. The number of viable spheroplasts did not decrease appreciably during $6 \mathrm{hr}$. of incubation but the proportion of rods decreased rapidly to $10^{-3}$ during the first 3 or $4 \mathrm{hr}$. of treatment with penicillin, and then more gradually. In Fig. $1(b)$, one of the two curves for rod number was obtained by diluting and plating the suspension without washing, while the other is based on the behaviour of washed cells. This result shows that there was little influence on the rod count even when penicillin was not washed out of the suspension before plating. Two sugar concentrations, 10 and $20 \%$, were also compared; Fig. $\mathbf{1}(c)$ shows that there is no real difference between them. On the basis of the results described above, incubation was carried out in penicillin and $20 \%$ sucrose for $4 \mathrm{hr}$. at $20^{\circ}$ to create conditions suitable for making spheroplasts.

After the spheroplasts were made the suspension, which had been in penicillin 
hypertonic penassay broth at $20^{\circ}$ for $4 \mathrm{hr}$., was centrifuged in a Serval Centrifuge (type SS-1) at about $36,000 \mathrm{~g}$ for $10 \mathrm{~min}$., the supernatant fluid decanted, and the organisms were resuspended in the same volume of $\mathrm{G} \& \mathrm{~T}$ medium containing $20 \%$ sucrose and $\mathbf{0 . 2} \% \mathrm{MgSO}_{4} \cdot 7 \mathrm{H}_{2} \mathrm{O}$ but no histidine. This procedure was repeated 3 times (two washings) in a $5^{\circ}$ cold room and the final suspension diluted tenfold in the same medium. During this procedure there was no appreciable death of spheroplasts.

The cell suspension thus obtained, which contained from $5 \times 10^{6}$ to $1 \times 10^{7}$ spheroplasts $/ \mathrm{ml}$. and was clear to the naked eye, was distributed as $2 \mathrm{ml}$. portions into more than a hundred (usually about two hundred) small tubes and incubated statically at $20^{\circ}$. During this incubation the numbers of viable spheroplasts and rods were counted by sampling one or two clear cultures every day.
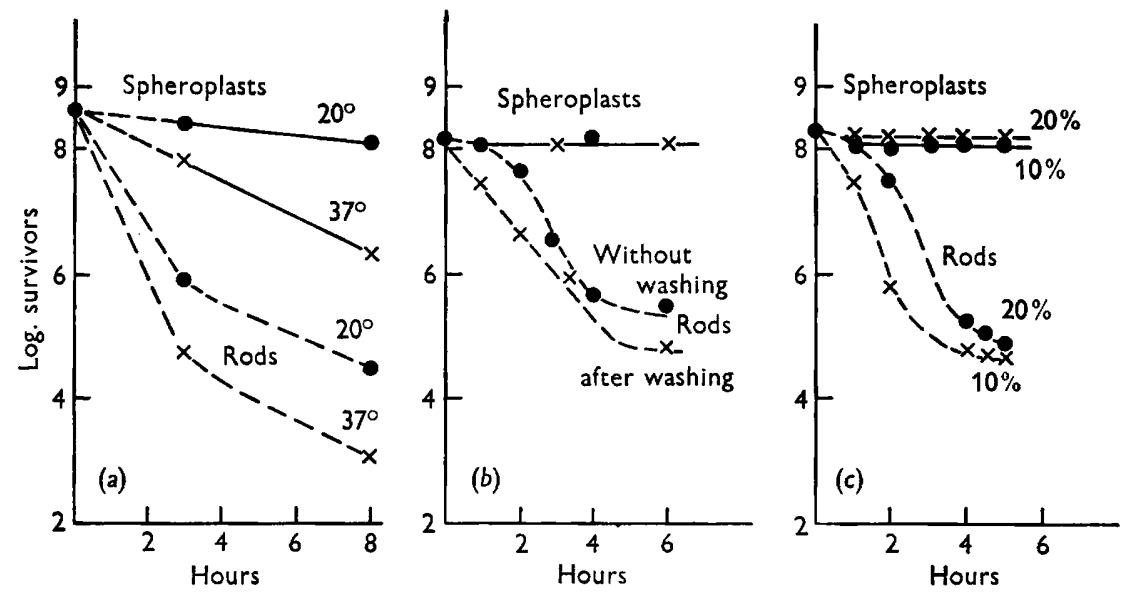

Fig. 1. (a) The effect of temperature on spheroplast formation. (b) The effect of washing twice with saline on spheroplast formation at $20^{\circ}$. (c) The effect of sugar concentration on spheroplast formation at $20^{\circ}$. Solid lines represent the viable spheroplast number and dotted lines the viable rod number.

Recovery of his- spheroplasts was achieved by plating washed suspensions on penassay agar plus $20 \%$ sucrose and $0 \cdot 2 \% \mathrm{MgSO}_{4} \cdot 7 \mathrm{H}_{2} \mathrm{O}$ where the spheroplasts produced rods and visible colonies. The fraction of spheroplasts which converted into rods was calculated from the number of spheroplasts in the suspension plated (enumerated in a Petroff-Hauser counting chamber) and the number of colonies produced; it varied in five different experiments from 56 to $109 \%$. In the experiment reported in Fig. $1 a$ conversion was $109 \%$ at $3 \mathrm{hr}$. and $80 \%$ at $8 \mathrm{hr}$.

The method of calculating the mutation rate of his ${ }^{-}$spheroplasts to his $^{+}$was based on the fact that if a spheroplast of his genotype is introduced into medium of high osmotic pressure devoid of both penicillin and histidine it is able to grow and will yield rod-shaped bacteria. The culture will become turbid through the overgrowth of such $h^{+} s^{+}$mutants, or of whatever $h^{+} s^{+}$rods were present in the spheroplast population. Consequently, the mean number of mutants, $m$, can be calculated from the frequency of clear cultures, $\boldsymbol{P}_{\mathbf{0}}$, and the zero term of the Poisson equation:

$$
\boldsymbol{P}_{0}=e^{-m} \text {. }
$$

Knowing that it takes about $\mathbf{1 2 5} \mathrm{hr}$. for a single his $^{+}$mutant spheroplast to form 
rods and overgrow a culture, one can use the $P_{0}$ at this time to estimate the average number, $m$, of $h i s^{+}$mutants per culture at the time of distribution. These mutants arose, of course, during previous growth.

Thereafter, while the suspensions are incubated under conditions of histidine starvation, mutations from $\mathrm{his}^{-}$to $\mathrm{his}^{+}$occur among the spheroplasts, and very occasionally among the rods, which result in the continued appearance of overgrowths. These new overgrowths increase the value of $m$ as calculated by equation (1). The rate of mutation/bacterium/hr. $(\mu)$ can be calculated (Ryan, 1955, 1959) from the equation:

$$
\mu=\frac{k m^{1}}{N_{0}\left(1-e^{-k t}\right)},
$$

where $m^{1}$ is now the average number of mutations ( $m$ at time $t_{2}$ minus $m$ at time $t_{1}$, which is any time after $125 \mathrm{hr}$., the time required for the overgrowth of preexisting $h i s^{+}$mutants), $t$ equals $t_{1}$ minus $t_{2}$ in hr., $N_{0}$ the number of bacteria present $125 \mathrm{hr}$. before $t_{1}$, and $k$ is the death rate constant calculated from the formulation:

$$
N=N_{0}^{1} e^{-k t} \text {, }
$$

$N_{0}^{1}$ being the number of bacteria at time 0 and $N$ the number at time $t$ in hr. Equation (1) can be used to calculate $m$ because each mutation in the stationary phase gives rise to one new mutant and where no mutations occur, the culture remains clear.

In cases in which death cannot be observed, the viable cell number remaining constant, the formulation

is used.

$$
\mu=\frac{m^{1}}{N_{0} t}
$$

Usually the frequency of $\mathrm{his}^{+}$mutations in an $\mathrm{his}^{-}$culture is about $2 \times 10^{-7}$ bacteria/hr. when normal rod-shaped bacteria and not spheroplasts are used. The chance of mutation/bacterium/hr. during growth is usually about $4 \times 10^{-8}$ and, in a stationary phase with glucose present, about $2 \times 10^{-9}$ (Ryan, 1955, 1959).

\section{RESULTS}

Representative results are shown in Fig. 2. Part $(a)$ shows the death curves of spheroplasts and rods. In this case, the rod number is nearly constant but the spheroplast number decreases rapidly in early stages and then gradually. Fig. $2(b)$ shows the behaviour of $m$ with time. The curve rises rapidly for the first $125 \mathrm{hr}$. and then gradually until $200 \mathrm{hr}$. The first rapid rise of the curve is caused by the preexisting $\mathrm{his}^{+}$mutants which have finished overgrowing at about $125 \mathrm{hr}$. Thereafter the gradual increase in $m$ is due to the overgrowth of is $^{+}$mutants which arose after the cultures were suspended in medium devoid of histidine. Eventually, when the cultures contained only about $3 \times 10^{5}$ cells $/ \mathrm{ml}$., mutations among them became too rare to be detected. The average frequency of pre-existing his ${ }^{+}$mutants in this experiment was about $2 \times 10^{-8}$ and the $\mu$ for stationary phase cells was about $2 \times 10^{-9} /$ bacterium $/ \mathrm{hr}$. Table 1 shows that these figures are not exceptional. The values calculated on the basis of spheroplast number more closely resemble those calculated for his- bacteria which had never been converted into spheroplasts. If it were supposed that the his ${ }^{+}$overgrowths observed were due to the small fraction of rods 
inevitably present in suspensions of spheroplasts, then their mutation rates would have to be unrealistically high and mutation would unexpectedly cease when the spheroplast number became small but the rod number remained as large as ever (Fig. 2). It is, on the contrary, judged that the his $^{+}$overgrowths were due to mutations in the spheroplasts. The somewhat smaller values for the initial frequency of
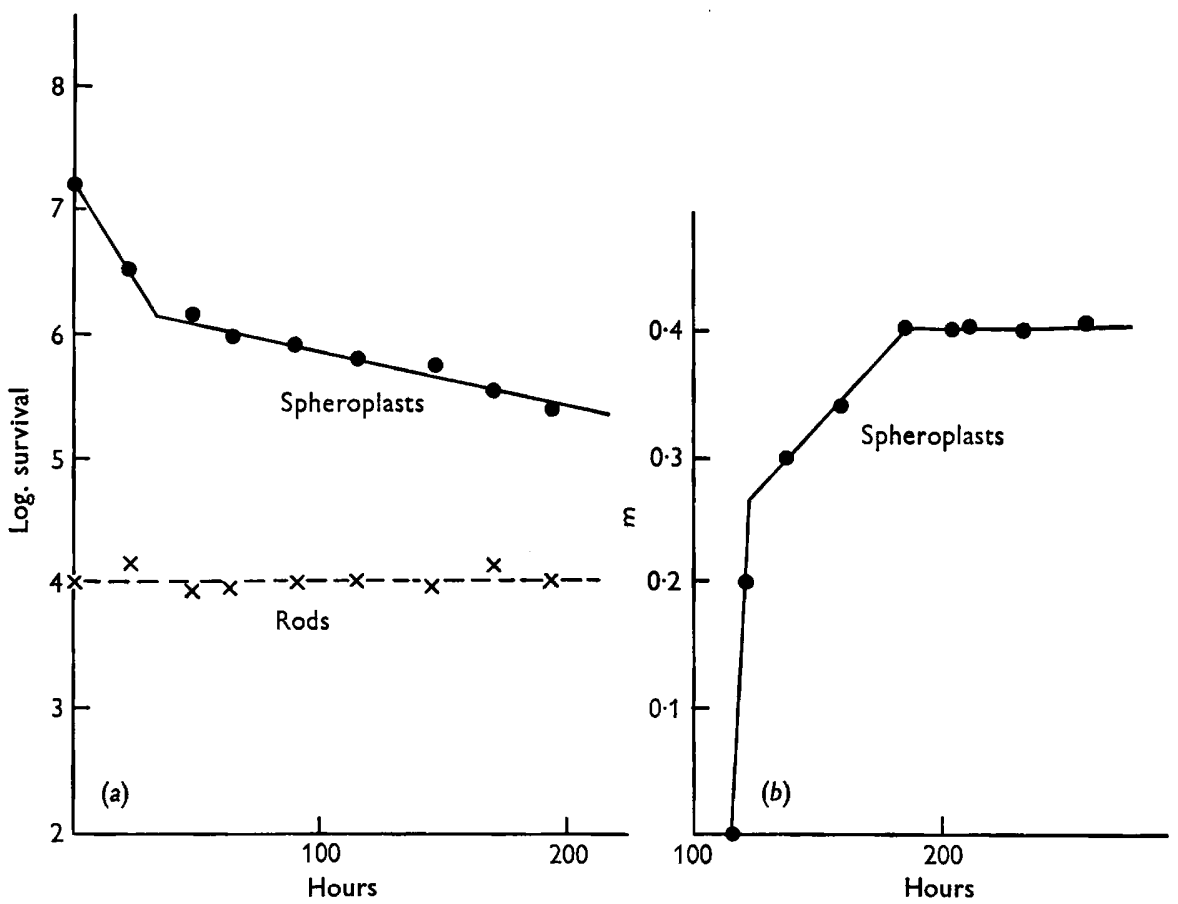

Fig. 2. Stationary phase mutation. Spheroplasts of Escherichia coli 15 his- made with penicillin were washed, resuspended, diluted in hypertonic $\mathbf{G} \& \mathbf{T}$ liquid medium without histidine and distributed as $2 \mathrm{ml}$. samples into 200 small tubes. They were incubated at $20^{\circ}$ and 4 determinations were made at each time of the number of surviving spheroplasts and rods and also of the number of clear cultures from which $m$ was calculated. $(a)$ The number of viable spheroplasts (solid line) and of viable rods (dotted line). (b) The average number of mutations, calculated from $P_{0}$, plotted against time. At the first break in the curve, $m$ is equivalent to a frequency of his $^{+}$back mutants in the original culture of about $2 \times 10^{-8}$; thereafter mutation occurred in the stationary phase at a rate, $\mu$, of $1.7 \times 10^{-9}$ until it could no longer be detected because of the small number of cells remaining.

his $^{+}$mutants calculated on the basis of spheroplast mutation as compared with that obtained for normal $\mathrm{his}^{+}$cells can be attributed to a lower efficiency in the recovery of $h^{+}{ }^{+}$spheroplasts, because of the use of synthetic medium (the his ${ }^{-}$spheroplasts recovered on penassay agar).

Experiments were made in which spheroplasts were burst in hypotonic penassay broth and then provided with sucrose, while another group was simply suspended from the beginning in the hypertonic medium. If mutations really occur in spheroplasts, one would not expect them in the suspension of burst cells but would expect them in the control suspension. These experiments ended in failure, because in the experimental culture the rods grew on nutrients liberated from the shocked spheroplasts. 
Table 1. Mutation rates from his- to his ${ }^{+}$in the stationary phase and frequencies of his ${ }^{+}$mutants among freshly grown his- cultures estimated on the basis of the number of spheroplasts and on the basis of the number of rods present

Calculated on the basis of spheroplasts

Initial frequency of

\begin{tabular}{|c|c|c|}
\hline Expt. & $h^{+}=\frac{m \text { at } 125 \mathrm{hr}}{N \text { at } 0 \mathrm{hr} .}$ & $\mu=\frac{k m^{1}}{N_{0}\left(1-e^{-k t}\right)}$ \\
\hline 1 (see Fig. 2) & $1.8 \times 10^{-8}$ & $1.7 \times 10^{-9}$ \\
\hline 2 & $3.5 \times 10^{-8}$ & $3.3 \times 10^{-9}$ \\
\hline 3 & $4.6 \times 10^{-8}$ & $3.4 \times 10^{-9}$ \\
\hline $\begin{array}{l}\text { values } \\
\text { obtained with } \\
\text { normal his- cel }\end{array}$ & $2 \times 10^{-7}$ & $2 \times 10^{-8}$ \\
\hline
\end{tabular}

Calculated on the basis of rods

Initial frequency of

$$
\begin{array}{cc}
\text { his }^{+}=\frac{m \text { at } 125 \mathrm{hr} .}{N \text { at } 0 \mathrm{hr} .} & \mu=\frac{m^{1}}{N t} \\
2.9 \times 10^{-5} & 1.5 \times 10^{-7} \\
4.6 \times 10^{-5} & 5.5 \times 10^{-6 *} \\
2.6 \times 10^{-5} & 5.2 \times 10^{-6 *} \\
2 \times 10^{-7} & 2 \times 10^{-9} \\
& 4 \times 10^{-8 *}
\end{array}
$$

* In these cases the rods increased in number so that the rate was calculated as the chance per bacterium per generation $(a=(m \ln 2) / N$, Ryan, 1955) and then converted to $\mu$ on the basis of a 50 min. generation time.

$\dagger$ Ryan (1955, 1959).

\section{DISCUSSIÓN}

Szybalski \& Pitzurra (1959) reported mutation to streptomycin-independence in spheroplasts of Escherichia coli produced with $\mathrm{LiCl}$. Although they did not prove that the mutants observed did not arise by mutation in the rods present, it seems likely that they took place in the spheroplasts. Their 'spheroplasts' were unlike ours, inasmuch as they did not burst in saline while in $20 \%$ sucrose the mutations occurred infrequently, if at all, even in the presence of chemical mutagens.

The present work with spheroplasts bears out previous experiments (Ryan, 1959) in strongly supporting the conclusion that mutation from his $^{-}$to his $^{+}$occurs in nondividing bacteria and that the mutated $\mathrm{his}^{+}$genotypes manifest their phenotypes in a non-dividing condition to grow in a medium without histidine.

However, the question still remains whether mutation requires DNA replication. The number of DNA-containing bodies could not be observed to increase in the spheroplasts which shrank somewhat during the stationary phase. Experiments to detect the replication of DNA by determining its quantity, and by the use of ${ }^{14} \mathbf{N}$ and ${ }^{15} \mathbf{N}$ with density gradient centrifugation, were negative. (Ryan, et al. 1961). Nonetheless, most investigations of induced mutation (Ryan, 1962) suggest that mutation occurs during DNA replication and support the theory that one of the mechanisms of mutation is pairing error. Errors in base pairing might be made not only during the replication of DNA but also by specific exchange when it is not replicating. This possibility is being examined by the use of isotopemarked base analogues and thymidine which may be incorporated into the DNA and induce mutations in non-dividing bacteria. It is also necessary to know whether a turnover of DNA was not observed because of isolation of the pool of DNA precursors, and whether an unusually high mutability characterizes an undetectably small turnover of DNA in non-dividing cells.

It is interesting to note that, although the his $^{-}$gene reverts spontaneously and in response to ultraviolet radiation (Ryan, Fried \& Schwartz, 1954) it does not respond 
to 2-aminopurine, 5-bromouracil or nitrous acid under conditions where auxotrophs are induced to form (Okada \& Ryan, unpublished results). This suggests that basepair insertions or deletions of the sort discussed by Crick, Barnett, Brenner \& Watts-Tobin (1961), unequal sister-strand crossing-over in a compound locus as proposed by Grigg \& Sergeant (1961) or transversions as defined by Freese (1961) may be involved. Yet proflavin, which induces auxotrophs, also does not revert the $h i s^{-}$gene. Moreover, the possibility has not been excluded that the mutable unit under investigation is composed of RNA or protein even though it is located in a DNA-containing body (Ryan \& Wainwright, 1954). Not enough evidence is as yet at hand to require rejection of the proposition that some natural mutations may result from copy-errors during the replication of the gene.

This work was supported in part by grants from the U.S. Public Health Service and the National Science Foundation. One of the authors (T. Nagata) was a Public Health Service Predoctoral Trainee in Genetics.

\section{REFERENCES}

Crick, F. H. C., Barnett, L., Brenner, S. \& Watts-Tobin, R. J. (1961). General nature of the genetic code for proteins. Nature, Lond. 92, 1227.

Freese, E. (1961). The molecular mechanisms of mutations. Proc. 5th int. Congr. Biochem.

Grigg, G. W. \& Sergeant, D. (1961). Compound loci and coincident mutation in Neurospora. Z. Vererbungslehre, $92,380$.

Lederberg, J. (1956). Bacterial protoplasts induced by penicillin. Proc. nat. Acad. Sci., Wash. 42, 574.

LeDerberg, J. \& ST Clatr, J. (1958). Protoplasts and L-type growth of Escherichia coli. J. Bact. 75, 143.

MUKaI, F. (1960). Interrelationship between colicine-sensitivity and phage-resistance. J. gen. Microbiol. 23, 539.

RYaN, F. J. (1955). Spontaneous mutation in non-dividing bacteria. Genetics, 40, 726.

RyaN, F. J. (1959). Bacterial mutation in a stationary phase and the question of cell turnover. J. gen. Microbiol. 21, 530.

Ryan, F. J. (1963). Bacteria I. Mutation and population genetics. In Methodology in Basic Genetics. Ed. by W. J. Burdette. (In the Press.)

Ryan, F. J., Fried, P. \& Mukai, F. (1955). A colicine produced by cells that are sensitive to it. Biochim. biophys. Acta, 18, 131.

Ryan, F. J., Fried, P. \& Schwartz, M. (1954). Nuclear segregation and the growth of clones of bacterial mutants induced by ultraviolet light. J. gen. Microbiol. 11, 380.

Ryan, F. J. \& Kiritani, K. (1959). Effect of temperature on natural mutation in Escherichia coli. J. gen. Microbiol. 20, 644.

Ryan, F. J., Narada, D. \& Schneider, M. J. (1961). Is DNA replication a necessary condition for spontaneous mutation? Z. Vererbungslehre, $92,38$.

Ryan, F. J., Rudner, R., Nagata, T. \& Krtani, Y. (1959). Bacterial mutation and the synthesis of macromolecules. Z. Vererbungslehre, $90,148$.

Ryan, F. J. \& WAINWRight, L. K. (1954). Nuclear segregation and the growth of clones of spontaneous mutants of bacteria. J. gen. Microbiol. 11, 364 .

Szybalski, W. \& Pitzurra, M. (1959). Mechanism of chemical mutagenesis. III. Induced mutations in spheroplasts of Escherichia coli. J. Bact. 77, 621. 